6 - ORIGINAL ARTICLE ISCHEMIA-REPERFUSION

\title{
Intra and postoperative evaluations of microcirculation and micro-rheological parameters in a rat model of musculocutaneous flap ischemia-reperfusion ${ }^{1}$
}

\author{
Zoltan Klarik', Robert Tamas $^{\mathrm{II}}$, Eniko Toth ${ }^{\mathrm{III}}$, Ferenc Kiss ${ }^{\mathrm{IV}}$, Eva L. Kovacs ${ }^{\mathrm{V}}$, Marta Jäckel ${ }^{\mathrm{VI}}$, Istvan Furka ${ }^{\mathrm{VII}}$, Norbert Nemeth ${ }^{\mathrm{VIII}}$ \\ DOI: http://dx.doi.org/10.1590/S0102-865020150080000006 \\ IMD, Postgraduate lecturer, Department of Operative Techniques and Surgical Research, Institute of Surgery, Faculty of Medicine, University of \\ Debrecen, Hungary. Technical procedures, analysis and interpretation of data, manuscript writing.

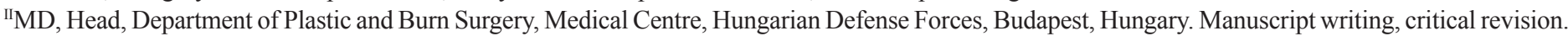

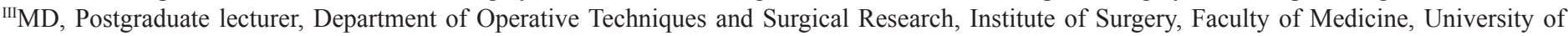 \\ Debrecen, Hungary. Acquisition of data, statistical analysis. \\ ${ }^{\text {IV }} \mathrm{PhD}$, Assistant lecturer, Department of Operative Techniques and Surgical Research, Institute of Surgery, Faculty of Medicine, University of Debrecen, \\ Hungary. Acquisition of data, statistical analysis, hemorheological examinations. \\ ${ }^{\mathrm{v}}$ Graduate student, Department of Operative Techniques and Surgical Research, Institute of Surgery, Faculty of Medicine, University of Debrecen, \\ Hungary. Acquisition of data, statistical analysis. \\ ${ }^{v} \mathrm{PhD}$, Associate Professor, Head, Department of Pathology, Medical Centre, Hungarian Defense Forces, Budapest, Hungary. Histological examinations. \\ ${ }^{\mathrm{VII}} \mathrm{PhD}$, Emeritus Professor, Department of Operative Techniques and Surgical Research, Institute of Surgery, Faculty of Medicine, University of \\ Debrecen, Hungary. Manuscript writing, critical revision. \\ VIIIPhD, Associate Professor, Head, Department of Operative Techniques and Surgical Research, Institute of Surgery, Faculty of Medicine, University \\ of Debrecen, Hungary. Intellectual and scientific content of the study, interpretation of data, manuscript writing.
}

\begin{abstract}
PURPOSE: To examine how the ischemia-reperfusion injury of latissimus dorsi-cutaneous maximus (LDCM) musculocutaneous flap affects the microcirculatory (flap's skin surface) and hemorheological parameters, and whether an intraoperative deterioration would predictively suggest flap failure in the postoperative period.

METHODS: Ten healthy male rats were subjected to the study. In Group I the left flap was sutured back after 2-hour, while the contralateral side was right after its elevation. In Group II the same technique was applied, but the pedicle of the left flap was atraumatically clamped for 2-hour. The contralateral side was left intact. On the flap skin surface laser Doppler tissue flowmetry measurements were done before and after and during the protocols applied in the groups. Microcirculatory and hemorheological examinations were done postoperatively.
\end{abstract}

RESULTS: The microcirculatory parameters significantly decreased during immobilization and ischemia. Afterwards, all the regions showed normalization. In the retrospective analysis there was a prominent difference between the microcirculatory parameters of necrotic and survived flap during the early postoperative days (1-3) in Group II. Erythrocyte aggregation and deformability showed only slight differences.

CONCLUSIONS: Two-hour ischemia and reperfusion caused deterioration in latissimus dorsi-cutaneous maximus flap microcirculation. Predicting the possible postoperative complication, the intraoperative laser Doppler measurement can be informative.

Key words: Microcirculation. Ischemia. Reperfusion. Hemorheology. Rats. 


\section{Introduction}

Reconstruction of large defects on the body requires flap surgeries ${ }^{1-3}$. The method of choice for reconstructive surgery is always depending on the region involved; however the common interest of such procedures is the flap survival rate ${ }^{1,4}$. Intraoperative and postoperative monitoring of the microcirculation is a reliable tool for assessment of flap viability after an unavoidable ischemiareperfusion $(\mathrm{I} / \mathrm{R})$ injury $^{5,6}$.

Throughout the years many flap monitoring methods had been developed but had not been congruence with each other regarding the best optimal technique ${ }^{4}$. Monitoring is especially important in case of microvascular free flap surgeries ${ }^{1,2}$. Clinical observation, such as evaluation of color, surface temperature change and capillary refill are essential component of postoperative follow-up, however they are greatly rely on the experience and the judgment of the observer ${ }^{7}$. More objective methods are available for detecting flap complications such as the laser Doppler systems, near infrared spectroscopy, intravital microscopy, orthogonal polarization microscope, transcutaneous $\mathrm{pO}_{2}^{8-14}$. All these may have their advantage or disadvantage ${ }^{4}$.

The laser Doppler flowmetry is known for monitoring microcirculations since 1961, but primary Stern demonstrated it practicability to evaluate the skin's microcirculation in $1975^{14}$, and since then it has been widely used to study the microcirculation of various tissues and in a clinical setting ${ }^{15}$. The monitoring of microcirculation could be essential, since during an ischemic insult tissue perfusion would be greatly decreased, consecutively causing deterioration in oxygenation, nutritional supply and temperature controlling, especially in the skin ${ }^{8,16}$. This would lead to necrosis, which would be further aggravated by increased number of inflammatory reaction and free radicals occurring during reperfusion ${ }^{17-19}$. The process would also worsen the hemorheological characteristics of red blood cells ${ }^{20}$. All together would usher microcirculatory disturbances, which would again lead the hypoperfusion.

In experimental setting, rats are frequently used for flap studies concerning flap's microcirculatory disturbances ${ }^{11}$, events occurring after ischemia ${ }^{17,18}$, effects of various drugs on flaps' viability $^{21}$ and evaluation of surgical safety ${ }^{22}$.

The aims of study was to investigate whether the skin microcirculation correlates on different sites on the flap's surface, and how the I/R injury affects the local microcirculation of the flap together with micro-rheological parameters. We were interested to see, whether an intraoperative deterioration would predictively suggest flap failure in the postoperative monitoring period.

\section{Methods}

\section{Experimental animals and operative technique}

The experiments were approved and registered by the University of Debrecen Committee of Animal Research (permission Nr.: 20/2011. UD CAR), in accordance with the relevant Hungarian Animal Protection Act (Law XVIII/1998).

Ten CD rats (bodyweight: $560.6 \pm 49.18 \mathrm{~g}$ ) were subjected to the study. The animals were anesthetized using sodium-thiopental $(60 \mathrm{mg} / \mathrm{kg}$ Thiopenthal, i.p.). They were in prone position and body temperature was maintained by a heating pad during the procedure. For microsurgical operations a Leica Wild M650 operative microscope was used, and video recordings were made. The animals were randomly divided into two groups.

In Group I, latissimus dorsi - cutaneous maximus musculocutaneous flaps were elevated on the left and right side. The skin and the cutaneous maximus muscle were cut in an elliptical shape from the posterior axillary line obliquely towards the $7^{\text {th }}$ thoracic vertebrae. The longitudinal axis of the flap was approximately $6 \mathrm{~cm}$ in length. The latissimus dorsi muscle was cut close to its origin between the border of the territory of the dominant pedicle (thoracodorsal artery) and the secondary segmental pedicles. The insertion of the muscle was left intact. The more prominent vessels were ligated. The left flap was sutured back after two hours, while the right side was reattached to its normal anatomical position after its preparation. During the immobilization, the flaps were placed over a wet surgical gauze swab. First, the latissimus dorsi muscle was sutured with $6 / 0$ absorbable suture material, then simple interrupted stitches were made in the skin with $4 / 0$ thread.

In Group II, the same technique was carried out, but the pedicle of the left flap was clamped atraumatically for 2 hours while the right side was left intact for 2 hours. Suturing of the flap was performed in the same manner as in group $I$.

The postoperative observation period was 1 week. Right after the procedure, on the $1^{\text {st }}$ and $3^{\text {rd }}$ day analgesia was given $(2.5$ $\mathrm{mg} / \mathrm{kg}$ Flunixin, s.c.). The animals' behavior was observed and wound inspection was carried out.

\section{Microcirculatory measurements}

A non-invasive laser Doppler tissue flowmetry was used (LD-01 laser Doppler tissue flowmetry monitoring system, Experimetria Ltd., Hungary) with a standard pencil probe (MNP100XP, Oxford Optronix Ltd., UK) placed on the surface of 
the flap. Based upon the Doppler shift effect when the laser beam is reflected from moving red blood cells, the device determines blood flux units (BFU) without dimension, which were registered for 20 seconds after stabilization of the signal. Using single-channel laser Doppler flowmetry, it is important to set the standards for the evaluation ${ }^{23-26}$, we have chosen the evaluation of the average BFU values of a standard time period of 20 seconds $^{20}$.

Over the skin non-invasive laser Doppler tissue flowmetry measurements were done before and after the flap preparation and during the protocols applied in the Group I and Group II. Intraoperatively, on the surface the BFU were recorded from three different marked sites: proximal, middle and distal regions of the flap. The proximal and distal sites were $1 \mathrm{~cm}$ from the edges, while the middle region was half the length of the longitudinal axis. Microcirculatory findings were also recorded on the $1^{\text {st }}, 3^{\text {rd }}, 5^{\text {th }}$ and $7^{\text {th }}$ postoperative days.

\section{Hemorheological measurements}

Blood samplings were done from lateral tail veins and hemorheological examinations (red blood cell aggregation and deformability) were carried out before the surgery and on the $7^{\text {th }}$ postoperative day under anesthesia before taking the biopsies for histological evaluation.

A Myrenne MA-1 erythrocyte aggregometer (Myrenne $\mathrm{GmbH}$, Germany) was used to measure red blood cell aggregation. The technique is based on light transmittance method. After disaggregating the blood sample by $600 \mathrm{~s}^{-1}$, the shear rate drops to zero ( $\mathrm{M}$ index) or to a low, $3 \mathrm{~s}^{-1}$ shear rate (M1 index) and according to the changes in light transmittance (disaggregation: low light transmittance, aggregation process: increasing light transmittance), the instruments calculates the aggregation index values at the $5^{\text {th }}$ or $10^{\text {th }}$ second of the aggregation process. Red blood cell deformability was measured by the LoRRca MaxSis Osmoscan device (Mechatronics BV, The Netherlands), where the elongation index (EI) was continuously analyzed in a controlled shear stress (SS) range. EI increases with red blood cell deformability ${ }^{27,28}$. Both micro-rheological parameters are important determinants of the microcirculatory pattern ${ }^{29,30}$.

\section{Macroscopic and histological examination}

In the postoperative period, daily photo documentation was carried out; any change in color and surface temperature $\left({ }^{\circ} \mathrm{C}\right)$ were recorded. The temperature was measured by placing the probe over the skin.
All animals on postoperative day 7 were anesthetized and samples for histopathological examinations were collected. Hematoxylin \& eosin staining and stain described by Lie et al. ${ }^{31}$ were used to detect morphological and ischemic changes in the muscle and to compare the outcome of the different protocols. The hematoxylin - basic fuchsin - picric acid stain is a non-enzymatic histochemical technique demonstrating early damages caused by ischemia in muscle ${ }^{31}$. At the end of the sampling, the animals were euthanized by overdosing of anesthetics.

\section{Statistical analysis}

Data are presented as mean (standard deviation). The pairwise comparison of intraoperative laser Doppler flowmetry data obtained from various measurement sites were carried out with Student's t-test or non-parametric Mann-Whitney rank sum test, while the changes during the time-frame of experiment within measurement sites were analyzed by one-way ANOVA and repeated measures ANOVA with Bonferroni or Dunn's post hoc test, depending on the normality of the data distribution. The significance level was set at $\mathrm{p}<0.05$.

\section{Results}

\section{Macroscopic observation and surface temperature}

In Group I, where 2-hour immobilization of the flap on the left and immediate reattachment of the flap on the right were done, we did not observe autophagy and skin necrosis.

In Group II, we observed two cases (I/R-3 and I/R-5 animals), where by the $7^{\text {th }}$ postoperative day the left flap became totally necrotic. During the first two days of the postoperative observation, there was no sign of necrosis, however by the $3^{\text {rd }}$ postoperative day we could see signs of venous insufficiency (color of the skin changed to purple and in some areas black) on the left side. By the $4^{\text {th }}$ postoperative day the percentages of necrotic areas to the total flap surface were $34.9 \%$ and $22.5 \%$ in I/R-3 and I/R-5 animal, respectively. During the 7-day follow-up period, the extent of necrosis was more prominent in the proximal region and the periphery of the flap in both animals, then it became confluent with the distal region. Similarly with the previous group, the 2-hour immobilization of the right flap did not cause skin necrosis.

Intraoperative temperature changes can be seen in Table 1. During the intraoperative period, the temperature significantly decreased for the period of the 2-hour immobilization and 2-hour ischemia in Group I and Group II, respectively. 
TABLE 1 - Intraoperative temperature of the flaps $\left[{ }^{\circ} \mathrm{C}\right]$.

\begin{tabular}{|c|c|c|c|c|}
\hline Group & Flap & Base & 120 & End of operation \\
\hline Group I & Left & $33.26 \pm 0.89$ & $30.76 \pm 1.04 *$ & $32.76 \pm 1.02$ \\
\hline \multirow[t]{2}{*}{ Group II } & Left & $32.38 \pm 1.39$ & $29.88 \pm 1.74 *$ & $32.2 \pm 0.68$ \\
\hline & Right & $32.84 \pm 1.21$ & $31.82 \pm 1.01$ & $32.78 \pm 0.96$ \\
\hline
\end{tabular}

$*_{\mathrm{p}}<0.05$ vs Base

\section{Histological examination}

With Hematoxylin and Eosin staining we observed leukocyte infiltration on both side (2-hour ischemia and 2-hour immobilization) in Group II (Figure 1 A and B). The samples from Group I. did not show difference.

Expressly, the latissimus dorsi muscle had significant ischemic injury -marked discoloration in red- in the 2-hour ischemia flap with Lie-staining (Figure 2A). The right flaps, where 2-hour immobilization was carried out, did not present any sign of ischemia (Figure 2B). In the $\mathrm{I} / \mathrm{R}-2$ animal the cutaneous maximus muscle had moderate signs of ischemia, while the latissimus dorsi muscle showed more expressed discoloration.
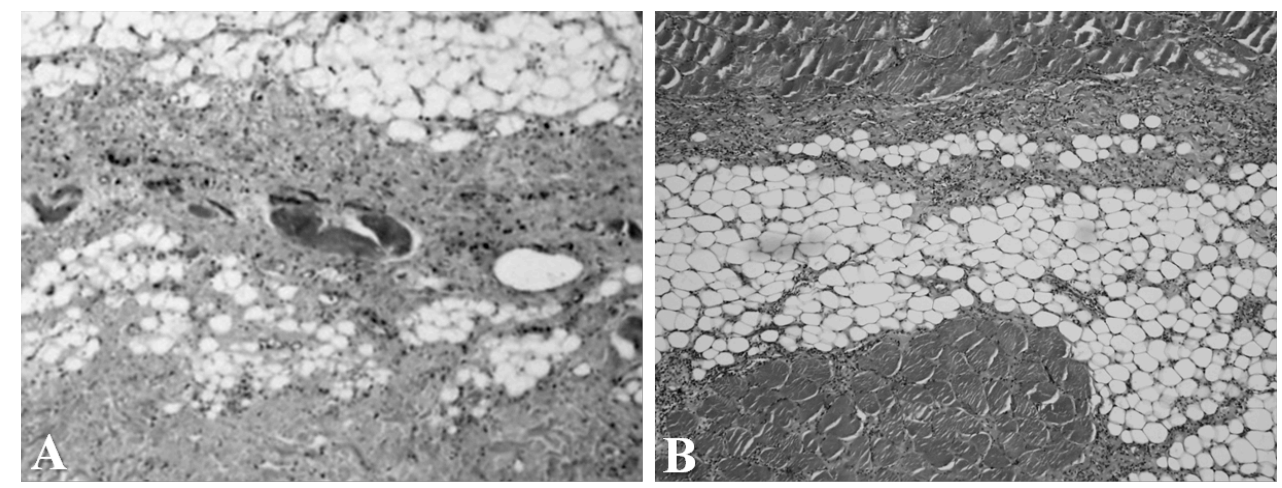

FIGURE 1 - Histological examination with H\&E staining A: Sample from the 2-hour ischemia flap of group II with leukocyte infiltration (magnification: 10X). B: Sample from the 2-hour immobilization flap of group II with leukocyte infiltration (magnification: x10).
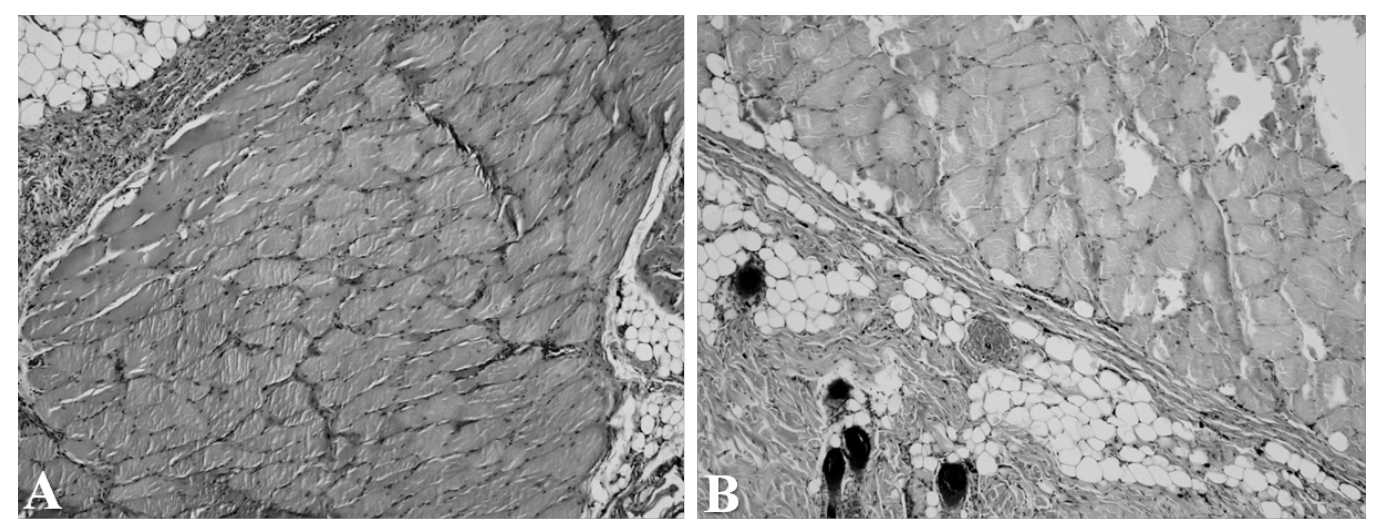

FIGURE 2 - Histological examination with Lie staining. A: Sample from the 2-hour ischemia flap of group II with prominent signs of ischemia: reddish discoloration. B: Sample from the 2-hour immobilization flap of group II without signs of ischemia (magnification: x10). 


\section{Microcirculation of the flaps}

In Group I, on the left flap the intraoperative base BFU values (proximal: $62.98 \pm 9.31$, middle: $50.64 \pm 11.23$, distal: $44.24 \pm 21.14)$ were significantly decreased during the surgical procedure (proximal: $49.8 \pm 10.91$, middle: $36.61 \pm 14.12$, distal: $25.49 \pm 16.56, \mathrm{p}<0.05$ ) and after 2-hour period (proximal: 28.78 \pm 9.17 , middle: $29.21 \pm 6.69$, distal: $18.269 \pm 7.48, \mathrm{p}<0.05)$, while on the right flap only at the end of procedure (proximal: $62.78 \pm 11.19$ vs. $45.42 \pm 22.45$, middle: $43.88 \pm 7.95$ vs. 33.09 $\pm 10,69$, distal: $38.04 \pm 11.24$ vs. $21.48 \pm 7.79, \mathrm{p}<0.05$ vs. Base) The difference was more demarcated in the middle and distal region of the flap. In the postoperative period, the values did stabilize and by the $7^{\text {th }}$ postoperative day, the measured parameters returned to the normal base values (Figure 3). Distinct deviations were observed among the regions in the same time frame, which was more eminent in the distal regions of the left and right flap. This distinction could be observed by the end of the operations (distal vs. proximal: $21.49 \pm 7.79$ vs. $45.42 \pm 22.45, \mathrm{p}<0.05$; distal vs. middle: $21.49 \pm 7.79$ vs. $33.09 \pm 10.69, \mathrm{p}<0.05)$.

A

\section{Group I}

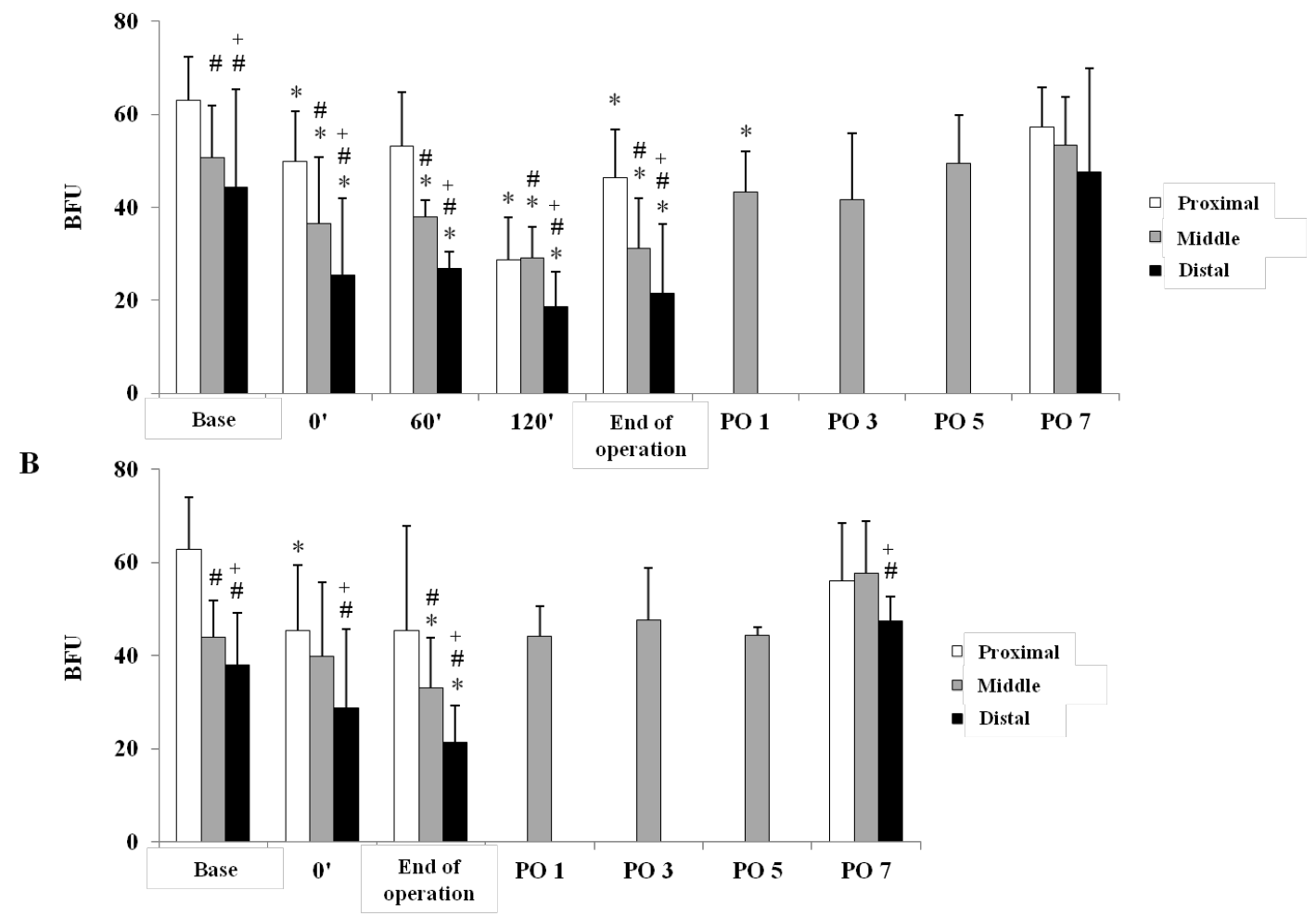

FIGURE 3 - Intraoperative and postoperative microcirculatory flow parameter values (blood flux unit, BFU) of the left side (A) and right side (B) flaps in Group I, measured on the skin surface of proximal, middle and distal flap regions.. ${ }^{*} \mathrm{p}<0.05$ vs. Base; $\# \mathrm{p}<0.05$ vs. Proximal; $+\mathrm{p}<0.05$ vs. Middle.

Intraoperatively in Group II, the left side -where 2-hour ischemia was induced- showed the expected significant $(\mathrm{p}<$ 0.05 vs. Base) decrease in the BFU values compared to its base in all measured regions (proximal: $63.2 \pm 7.57$, middle: $42.69 \pm$ 7.28, distal: $40.0 \pm 7.28$ ) (Figure 4). At 60' and 120', the level of significance was more prominent (proximal: $16.71 \pm 9.49$ and $20.98 \pm 4.18$, middle: $7.24 \pm 6.05$ and $10.44 \pm 8.91$, distal: $8.56 \pm 3.35$ and $16.84 \pm 10.19, \mathrm{p}<0.001$ vs. Base). However as it was previously described, two flaps became necrotic during the postoperative period and their values were separately analyzed and compared the three survival flaps. As Figure 5 shows, by the end of the operation the parameters of the middle regions showed indicative difference retrospectively, and by the $1^{\text {st }}$ postoperative day it was more significant. The distal regions of the flaps demonstrated similar degree of decrement in their BFU values, but during the postoperative evaluation having regard to the suture lines this region's parameters were not recorded. 
A

\section{Group II}

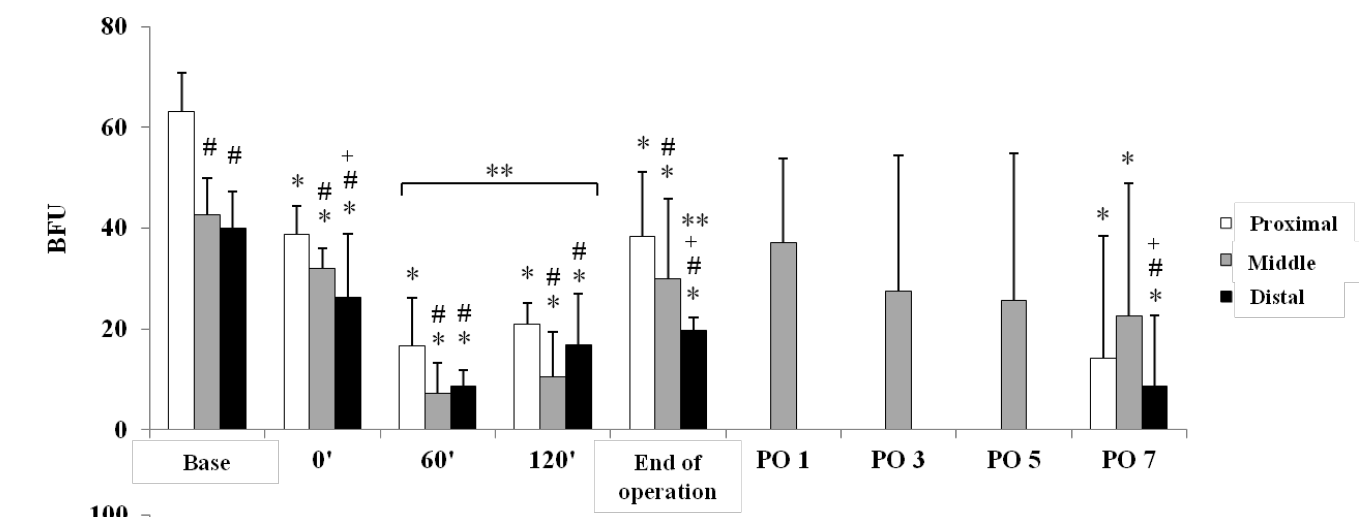

B

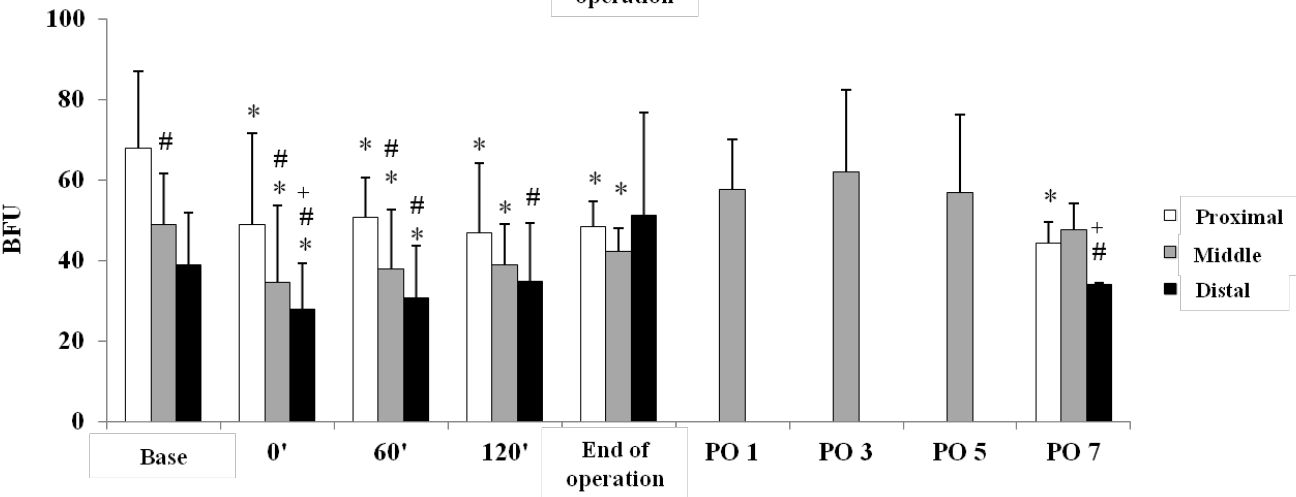

FIGURE 4 - Intraoperative and postoperative microcirculatory flow parameter values (blood flux unit, BFU) of the left side (A) and right side (B) flaps in Group II, measured on the skin surface of proximal, middle and distal flap regions. ${ }^{*} \mathrm{p}<0.05$ vs. Base; $\# \mathrm{p}<0.05$ vs. Proximal; $+\mathrm{p}<0.05$ vs. Middle, ${ }^{* *} \mathrm{p}<0.05$ vs. Right flap.

Parallel with the color change from the $3^{\text {rd }}$ postoperative day, the skin over the flaps turned fully necrotic, and microcirculatory $\mathrm{BFU}$ values could not be measured. Two hours of immobilization in this group caused significant deterioration more prominently in the proximal and middle region by the end of the operation.
Throughout the experiment in Group II, we observed significant microcirculatory parameter difference among the three regions in both groups. Interestingly, this divergence disappeared between the proximal and middle regions by the end of the postoperative period.

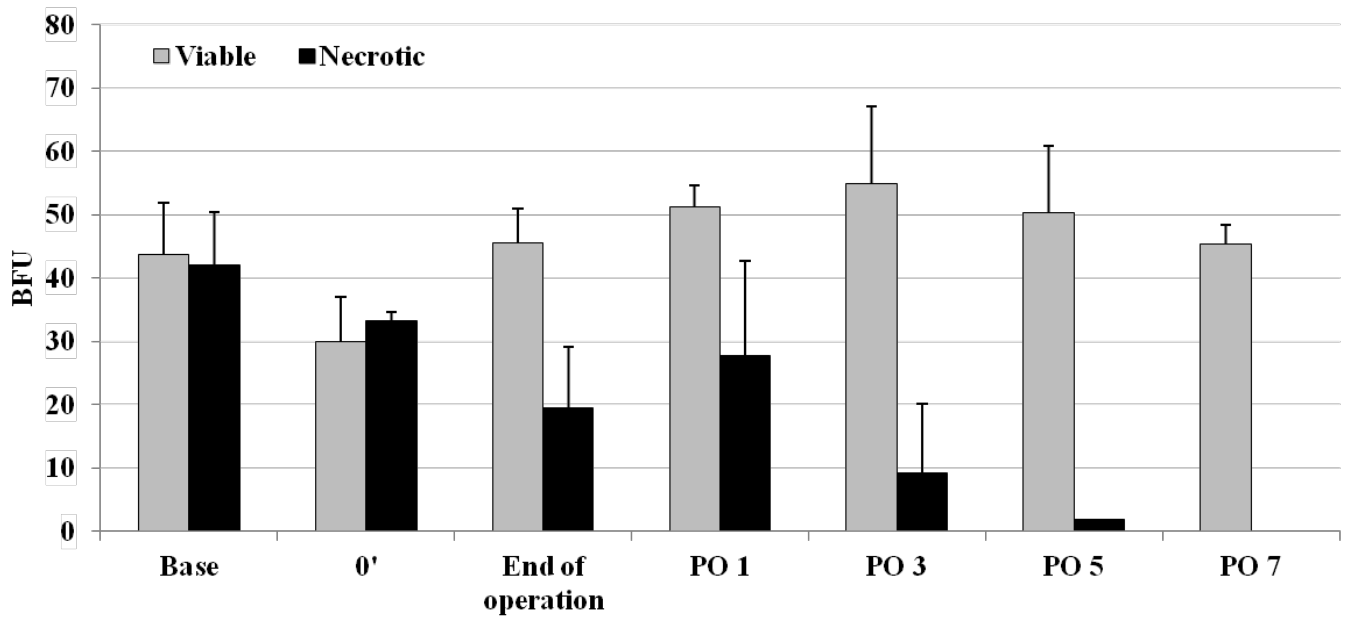

FIGURE 5 - Retrospective demonstration of blood flux unit (BFU) values of the viable (3) and necrotic (2) left flaps' middle regions form Group II. 


\section{Hemorheological parameters}

Figure 6 illustrates the red blood cell deformability changes. The curve shows the elongation index (EI) of the red blood cells in the function of shear stress (SS). The preoperative and $7^{\text {th }}$ postoperative days' parameters did not differ; at most of the shear stress values the parameters were overlapping.

The aggregation of red blood cells did not demonstrate immense difference, but by the $7^{\text {th }}$ postoperative day in Group II M1 parameters at the $5^{\text {th }}$ and $10^{\text {th }}$ seconds of the aggregation process were significantly decreased compared to the preoperative values (Figure 7)
Group I

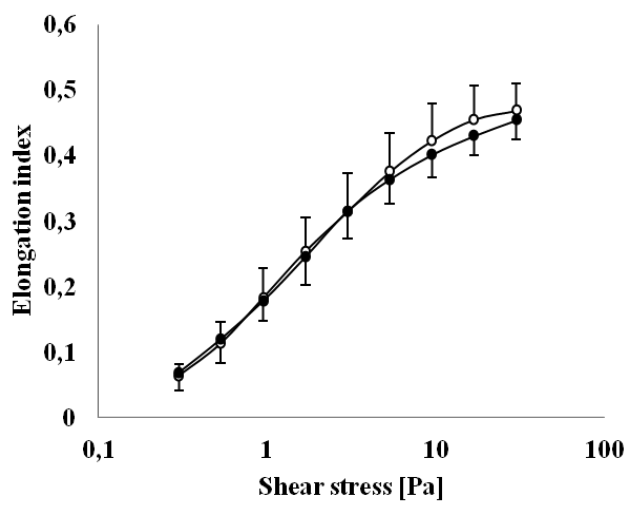

A

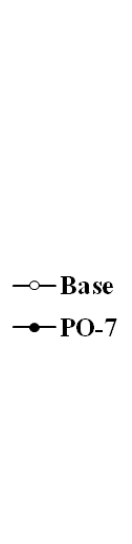

FIGURE 6 - Deformability of red blood cells in Group I and Group II preoperatively (Base) and on the $7^{\text {th }}$ postoperative day (PO-7). The graph shows the elongation index (EI) of the red blood cells in the function of shear stress (SS).

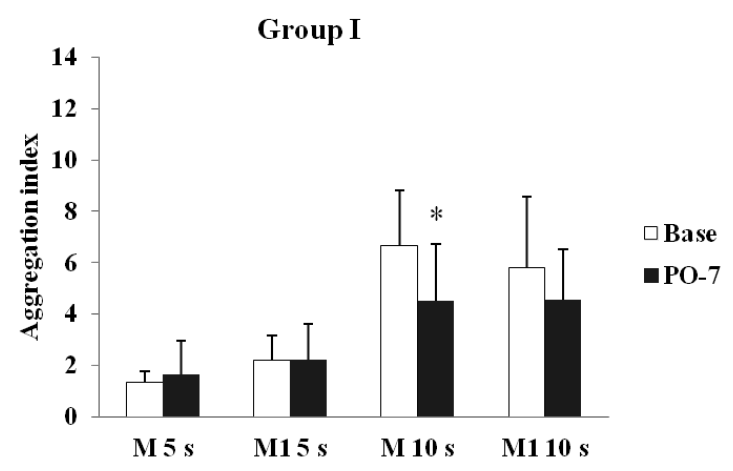

A

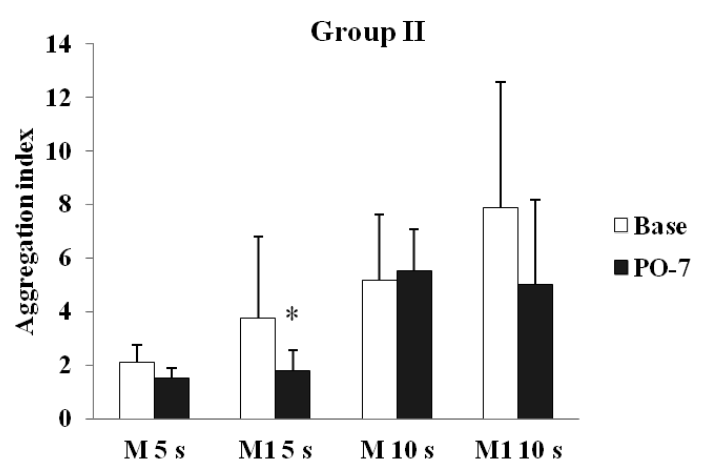

B

FIGURE 7 - Aggregation of red blood cells in Group I and Group II preoperatively (Base) and on the $7^{\text {th }}$ postoperative day (PO-7). ${ }^{*} \mathrm{p}<0.05$ vs. Base.

\section{Discussion}

Free flap transplantation became the method of choice for the treatment of large soft tissue defect and reconstruction, therefore postoperative monitoring of the flap viability is important, since early detection of failure have higher change to be treated and flap salvage. Major factors affecting the flaps viability is the duration of ischemic time (primary and secondary), surgical technique (method of performing anastomosis), health status of the patient (diabetes mellitus, irradiation), and adequate pre- and postoperative care (anticoagulation) and monitoring ${ }^{4}$.

The aim of the study was to investigate whether the changes in microcirculation measured with laser Doppler flowmetry correlates with the systemic hemorheological changes during an ischemia-reperfusion injury of a musculocutaneous flap model in rats. We hypothesized that the microcirculation 
measured at different regions of the flap's skin would deteriorate and normalize with the applied protocol and there would be a demarcated difference between the microcirculatory parameters in the early postoperative period of the necrotic and viable flaps.

For the evaluation of microcirculation during flap ischemia-reperfusion many techniques have been developed. Observation and assessment of color, temperature ${ }^{6}$, capillary refills and swelling is used especially in monitoring cutaneous or musculocutaneous flaps ${ }^{4,7}$. Hand held Doppler ultrasonography, laser Doppler, implantable Doppler, pulsoximetry, near infrared spectroscopy, tissue $\mathrm{pH}$, transcutaneous oxygen tensions, bioelectrical impendence measurements are objective methods for detecting complication in the postoperative period. Clinical observation is subjective and continuous observation requires time and an observer ${ }^{4}$.

The laser Doppler flowmetry measures the cutaneous capillary flow by the Doppler shift in the laser beam backscattering from moving red blood cells, which is detected by the photodetectors and processed. The frequency change and the amplitude between the transmitted and reflected light is directly proportional to the velocity and number of red blood cells. It does not depend on the direction of the movement. Since the collected data is not an absolute parameter, it determines a relative value. Moreover the changes in pattern would indicate impairment of microcirculation. Jones et al. ${ }^{8}$ concluded that reduction in the recorded parameters over a 2-hour period after a free flap surgery would indicate reduction in blood flow of the flap and would require surgical intervention. In a more recent study, it was proved that laser Doppler flowmetry is an essential and reliable tool in the aid of the decision to revise microvascular anastomoses. Among the 196 observed patients, the cluster of changes compared to the baseline in the superficial and deep blood flow parameters indicate underlying deterioration process, which would need an immediate correction $^{10}$.

Inoue etal. ${ }^{17}$ investigated tolerance of skinmicrocirculation to ischemia and reperfusion injury parallel with increasing age in rat epigastric skin flap model by using laser Doppler flowmetry. They described that the skin blood flow decreased to 30 to $50 \%$ of the baseline following ischemia but never researched $0 \%$. We found similar changes in microcirculatory values during the 2-hour ischemic event, where in the I/R group, the left (clamped) LDCM flap's cutaneous BFU values decreased 67\% compared to the baseline. The right side of the same group, where 2-hour immobilization was induced, the parameters decreased only by $20 \%$ of the baseline. One possible explanation of the detectable microcirculation during the ischemia is that the flowmeter may detect multidirectional movement ${ }^{17}$ or vibration of red blood cells even through there is no blood flow ${ }^{12}$, which may be influenced by the respiratory movements.

Interestingly, when we separately analyzed the BFU values of the animals $(n=3)$ in the $I / R$ group with viable flaps by the $7^{\text {th }}$ postoperative day from the animals $(n=2)$, whose flap became ischemic we found that by the end of the 2-hour ischemia the viable flaps and ischemic flap parameters dropped by $88 \%$ and $59 \%$, respectively. However, at the end of the operation viable flaps' BFU values were only $12 \%$ less than their baseline, and ischemic flaps' values were still $52 \%$ below their baseline. Although in this group we had five animals, statistical conclusion cannot be drawn, but with larger numbers of experimental animals, this phenomenon is needed to be investigated further since it might be a possible predicting factor of flaps' survivability in rat models.

Temperature assessment is also a reliable tool for free flap monitoring. Since it correlates with flap's capillary microcirculation $^{6}$, it is frequently used in postoperative observation. It is accounted that a $1-2^{\circ} \mathrm{C}$ uniform temperature drop would indicate venous compromise, while a $2-3^{\circ} \mathrm{C}$ drop would be indicative for arterial occlusion ${ }^{4}$. Papillion et al. ${ }^{5}$ observed a $2{ }^{\circ} \mathrm{C}$ temperature difference between the flap failure group and surviving flaps during the first postoperative day by using infrared surface temperature monitoring. Intraoperatively, we experienced $\sim 2.5^{\circ} \mathrm{C}$ drop of skin temperature by the end of the 2-hour ischemia on the left flap. The 2-hour immobilization caused $\sim 1^{\circ} \mathrm{C}$ temperature drop. By the end of the operation, both sides' temperature returned to the baseline.

The micro-rheological parameters, such as red blood cell deformability and aggregation are greatly influenced by the effect of ischemia-reperfusion. Mostly on the $1^{\text {st }}-3^{\text {rd }}$ postoperative days this is related to the inflammatory reactions, hemodynamic alteration, induction of free-radicals and mediators, acute phase reactions and changes in the coagulation state. In the early hours of reperfusion metabolic and free radical alterations are more dominant. All these factors can further aggravate the postoperative complication of microvascular tissue transfer. Pathologically altered red blood cells show reduction in their deformability, thus leading to capillary occlusion and decreased oxygen supply for the tissues $^{29}$. Red blood cells aggregation is enhanced under oxidative stress and the aggregates form a cell free layer near the wall, which would promote platelet interaction with the vessel wall. Also the augmented aggregation process leads to increased blood viscosity, which further promote reduced blood flow rate (dominantly due to metabolic and free radical alterations $)^{31}$.

Most likely, the majority of these reactions (metabolic 
disturbance and induction of free radicals) are passed off by the $7^{\text {th }}$ postoperative day; thereby we did not found any definitive difference on this day. However, the presence of inflammation (leukocyte infiltration) was still visible in the histological examinations, which might caused by systemic effects rather local. These factors may play role in the alteration of aggregation parameters, which differ from the result of previous early reperfusion and early postoperative day investigations.

In our previous study, 1-hour ischemia-reperfusion of a latissimus dorsi muscle flap in the canine resulted in local changes of white blood cells' distribution and increased red blood cell aggregation, and attributed the cause to the induction of local metabolic inflammatory reactions in the first 60 minutes of reperfusion ${ }^{32}$. Furthermore, in various other I/R experimental models (kidney, testicle, small intestine) the red blood cell deformability deteriorated during the ischemic event as well as on the $1^{\text {st }}$ and $3^{\text {rd }}$ postoperative days ${ }^{33}$. In our current study, we did not observe significant differences in the hemorheological parameters of the two groups. Still, it is little known about the connection between the local and systemic rheological changes, especially during ischemia-reperfusion ${ }^{20}$.

\section{Conclusions}

The 2-hours ischemia and the following reperfusion caused significant deterioration in flaps' microcirculation. In the prediction of the possible postoperative complication (e.g.: necrosis, thrombosis), the intraoperative laser Doppler measurement may have an important, predictive role.

\section{References}

1. Kruse AL, Luebbers HT, Grätz KW, Obwegeser JA. Factors influencing survival of free-flap in reconstruction for cancer of the head and neck: a literature review. Microsurgery. 2010;30(3):242-8. doi: $10.1002 /$ micr.20758.

2. Brown JS, Devine J-C, Magennis P, Sillifant P, Rogers SN, Vaughan ED. Factors that influence the outcome of salvage in free tissue transfer. Br J Oral Maxillofac Surg. 2003 Feb;41(1):16-20. PMID: 12576035 .

3. Miyamoto S, Kayano S, Umezawa H, Fujiki M, Nakao J, Sakuraba M. Efficient design of a latissimus dorsi musculocutaneous flap to repair large skin defects of the upper back. Microsurgery. 2014 Jan;34(1):20-2. doi: 10.1002/micr.22108.

4. Salgado CJ, Moran SL, Mardini S. Flap monitoring and patient management. Plast Reconstr Surg. 2009 Dec;124(6Suppl):e295-302. doi: 10.1097/PRS.0b013e3181bcf07b.

5. Papillion P, Wong L, Waldrop J, Sargent L, Brzezienski M, Kennedy W, Rehm J. Infrared surface temperature monitoring in the postoperative management of free tissue transfers. Can J Plast Surg. 2009 Fall;17(3):97-101. PMID: 20808752.

6. Kraemer R, Lorenzen J,Knobloch K, Papst S, Kabbani M, Koennecker
S, Vogt PM. Free flap microcirculatory monitoring correlates to free flap temperature assessment. J Plast Reconstr Aesthet Surg. 2011 Oct;64(10):1353-8. doi: 10.1016/j.bjps.2011.04.030.

7. Chao AH, Lamp S. Current approaches to free flap monitoring. Plast Surg Nurs. 2014 Apr-Jun;34(2):52-6. doi: 10.1097/ PSN.0000000000000037.

8. Jones BM, Mayou BJ. The Laser Doppler flowmeter for microvascular monitoring: a preliminary report. Br J Plast Surg. 1982 Apr;35:147-9. PMID: 6211205.

9. Islamoglu K, Ozgentas E. Monitoring of rat skin flap ischemia by bioelectrical impedance measurements. Ann Plast Surg. 2001;47:534-9. PMID: 11716266.

10. Mücke T, Rau A, Merezas A, Loeffelbein DJ, Wagenpfeil S, Mitchell DA, Wolff KD, Steiner T. Identification of perioperative risk factor by laser-doppler spectroscopy after free flap perfusion in the head and neck: a prospective clinical study. Microsurgery. 2014 Jul;34(5):345-51. doi: 10.1002/micr.22206.

11. Hellner D, Schmelzle R. Laser Doppler monitoring of free microvascular flaps in maxillofacial surgery. J Craniomaxillofac Surg. 1993 Jan;21:25-9. PMID: 8445051.

12. Liss AG, Liss P. Use of a modified oxygen microelectrode and laser-Doppler flowmetry to monitor changes in oxygen tension and microcirculation in a flap. Plast Reconstr Surg. 2000 May;105:20728. PMID: 10839404.

13. Payette JR, Kohlenberg E, Leonardi L, Pabbies A, Kerr P, Liu KZ, Sowa MG. Assessment of skin flaps using optically based methods for measuring blood flow and oxygenation. Plast Reconstr Surg. 2005 Feb;115(2):539-46. PMID: 15692360.

14. Stern MD. In vivo evaluation of microcirculation by coherent light scattering. Nature. 1975 Mar 6;254(5495):56-8. PMID: 1113878.

15. Stern MD, Lappe DL, Bowen PD, Chimosky JE, Holloway GA Jr, Keiser HR, Bowman RL. Continuous measurement of tissue blood flow by laser-Doppler spectroscopy. Am J Physiol. 1977 Apr;232(4):H441-8. PMID: 556582.

16. Essex TJ, Byrne PO. A laser Doppler scanner for imaging blood flow in skin. J Biomed Eng. 1991 May;13:189-94. PMID: 1870327.

17. Inoue S, Asai Y, Kawai Y. Age-dependent changes of postischemic reperfusion in rat skin. Ann Plast Surg. 2003 Jan;50(1):64-70. PMID: 12545111.

18. Siemionow M, Arslan E. Ischemia/reperfusion injury: a review in relation to free tissue transfers. Microsurgery. 2004;24(6):468-75. PMID: 15378577.

19. Eltzschig HK, Eckle T. Ischemia and reperfusion--from mechanism to translation. Nat Med. 2011 Nov 7;17(11):1391-401. doi: 10.1038/ nm.2507.

20. Nemeth N, Furka I, Miko I. Hemorheological changes in ischemiareperfusion: an overview on our experimental surgical data. Clin Hemorheol Microcirc. 2014;57(3):215-25. doi: 10.3233/CH131648.

21. Zhang F, Lineaweaver W. Acute and sustained effects of vascular endothelial growth factor on survival of flaps and skin grafts. Ann Plast Surg. 2011 May;66(5):581-2. doi: 10.1097/ SAP.0b013e3182057376.

22. Reichenberger M, Gazyakan E, Kohler S, Germann G, Engel H. A new, custom-made device for flap protection in experimental animals. Microsurgery. 2009;29(6):504-6. doi: 10.1002/micr.20654.

23. Obeid AN, Barnett NJ, Dougherty G, Ward G. A critical review of laser Doppler flowmetry. J Med Eng Technol. 1990 SepOct;14(5):178-81. PMID: 2231661.

24. Szijarto A, Hahn O, Lotz G, Schaff Z, Madarász E, Kupcsulik PK. Effect of ischemic preconditioning on rat liver microcirculation monitored with laser Doppler flowmetry. J Surg Res. 2006 Mar;131(1):150-7. PMID: 16256139. 
25. Hu W, Yang M, Chang J, Shen Z, Gu T, Deng A, Gu X. Laser Doppler perfusion imaging of skin territory to reflect autonomic functional recovery following sciatic nerve autografting repair in rats. Microsurgery. 2012 Feb;32(2):136-43. doi: 10.1002/micr.20974.

26. Nemeth N, Lesznyak T, Brath E, Acs G, Nagy A, Pap-Szekeres J, Furka I, Miko I. Changes in microcirculation after ischemic process in rat skeletal muscle. Microsurgery. 2003;23(5):419-23. PMID: 14557994.

27. Baskurt OK, Boynard M, Cokelet GC, Connes P, Cooke BM, Forconi S, Liao F, Hardeman MR, Jung F, Meiselman HJ, Nash G, Nemeth N, Neu B, Sandhagen B, Shin S, Thurston G, Wautier JL; International Expert Panel for Standardization of Hemorheological Methods. New guidelines for hemorheological laboratory techniques Clin Hemorheol Microcirc. 2009;42(2):75-97. doi: 10.3233/CH2009-1202.

28. Hardeman MR, Goedhart PT, Shin S. Methods in hemorheology, In: Baskurt OK, Hardeman MR, Rampling MW, Meiselman HJ, eds. Handbook of hemorheology and hemodynamics. Amsterdam: IOS Press; 2007. p.242-66.

29. Baskurt OK, Meiselman HJ. Blood rheology and hemodynamics. Semin Thromb Hemost. 2003 Oct;29(5):435-50. PMID: 14631543.

30. Baskurt OK. Mechanism of Blood Rheology Alterations. In: Baskurt OK, Hardeman MR, Rampling MW, Meiselman HJ, eds. Handbook of hemorheology and hemodynamics. Amsterdam: IOS Press; 2007 p.170-90.

31. Lie JT, Holley KE, Kampa WR Titus JL. New histochemical method for morphologic diagnosis of early stages of myocardial ischemia. Mayo Clin Proc. 1971 May;46(5):319-27. PMID: 4102906.

32. Tamas R, Nemeth N, Brath E, Sasvari M, Nyakas C, Debreczeni B, Miko I, Furka I. Hemorheological, morphological, and oxidative changes during ischemia-reperfusion of latissimus dorsi muscle flaps in a canine model. Microsurgery. 2010 May;30(4):282-8. doi: 10.1002/micr.20699.

33. Nemeth N, Kiss F, Klarik Z, Peto K, Vanyolos E, Toth L, Furka I, Miko I. Testicular ischemia-reperfusion may later micro-rheological parameters in laboratory rats. Clin Hemorheol Microcirc. 2014;57(3):243-53. doi: 10.3233/CH-131664.

\section{Acknowledgement}

The technical staff of the Department of Operative Techniques and Surgical Research, University of Debrecen.

\section{Correspondence:}

Norbert Nemeth

Department of Operative Techniques and Surgical Research

Institute of Surgery, Faculty of Medicine

University of Debrecen

H-4032 Debrecen, Nagyerdei krt. 98

P.O. Box: 21 Hungary

Phone/Fax: +36-52-416-915

nemeth@med.unideb.hu

Received: Apr 11, 2015

Review: June 14, 2015

Accepted: July 152015

Conflict of interest: none

Financial source: none

${ }^{1}$ Research performed at Department of Operative Techniques and Surgical Research, Institute of Surgery, Faculty of Medicine, University of Debrecen, Hungary. 